\title{
25 Research Soure \\ Comparison of Forces Applied During Inserting A Cementless Femoral Stem Versus A Test To Failure: A Pilot Trial
}

Toni Wendler ( $\nabla$ toni.wendler@medizin.uni-leipzig.de )

Leipzig University: Universitat Leipzig https://orcid.org/0000-0001-7890-178X

\section{Stefan Schleifenbaum}

Leipzig University: Universitat Leipzig

Torsten Prietzel

Zeisigwaldkliniken Bethanien Chemnitz

Robert Möbius

Leipzig University: Universitat Leipzig

Andreas Roth

Leipzig University: Universitat Leipzig

\section{Dirk Zajonz}

Leipzig University: Universitat Leipzig

\section{Research}

Keywords: Assembly force, Femoral stem insertion, Intraoperative proximal femur fracture, Total hip arthroplasty, Biomechanical study

Posted Date: June 8th, 2021

DOl: https://doi.org/10.21203/rs.3.rs-571821/v1

License: (c) (i) This work is licensed under a Creative Commons Attribution 4.0 International License. Read Full License 


\section{Abstract \\ Background}

The increasing number of total hip arthroplasties (THA) and the more common use of uncemented stems are leading to an increasing incidence of intraoperative proximal femoral fractures (IPFF), making them a clinically relevant complication. When inserting the stem, the surgeon has to find a compromise between sufficient anchorage and the risk of fracture. Only a few biomechanical studies investigated forces that are necessary, or already risky, when inserting a femoral stem. Therefore, the aim of the study was to determine the forces occurring during the insertion of the stem and the forces that lead to IPFF.

\section{Methods}

Two female chemically untreated fresh-frozen human cadavers, aged 71 and 83 years and weighed $54 \mathrm{~kg}$ and $65 \mathrm{~kg}$ respectively, underwent left and right implantation of a THA stem by an experienced orthopaedic surgeon. The insertion of the stem was followed by a failure test, in which the surgeon hit the stem so hard that a fracture occurred. The forces, occurred while insertion and test to failure, were measured using an impulse hammer.

\section{Results}

The observed forces varied greatly. Over the four performed implantations, the forces ranged from 1317.7 $\mathrm{N}$ to $4347.5 \mathrm{~N}$ during insertion, and from $526.5 \mathrm{~N}$ to $7383.9 \mathrm{~N}$ during the failure test. The comparison between insertion versus failure test showed significantly higher peak forces $(P<0.001, P<0.001, P=$ 0.002 ) in the failure test for implantations 1,3 and 4 . The comparison was not possible for implantation 2 because of a sensor error.

\section{Conclusions}

The biomechanical experiments presented in this study have shown that even with the small number of implantations, significantly higher hammering forces were required to cause a visually or acoustically perceptible IPFF than were necessary for adequate seating of the femoral stem. However, as fractures often cannot be perceived intraoperatively, it is important to advance the development of supporting systems for intraoperative use.

\section{Background}

Total hip arthroplasty (THA) is one of the most common procedures in industrialised countries [1, 2]. Especially the implantation of cementless stems has become widespread and established as a leading procedure. As early as the 1980 s, different endoprostheses were developed concerning stem geometry. 
The main distinguishing characteristics are the design and the surface of the prosthesis. Clinical results have improved continually due to advances in these areas $[3,4]$. Today, the most commonly used stem design is closely associated with the name of Lorenzo Spotorno. The primary anchorage of the classic Spotorno stem is mainly metaphyseal according to the press-fit principle [5]. The success of this principle is based on a guideline of the following four parameters: age, gender, degree of osteoporosis and the anatomical characteristics of the femur $[5,6]$. When an adequate indication is given, the clinical outcome in terms of long term survivorship has been proven $[7,8]$. However, a high incidence of intraoperative calcar fractures using a Spotorno stem has been reported in the literature. Even after adequate implant positioning by experienced surgeons, the risk of calcar fractures was shown to be significantly increased $[9,10]$. Intraoperative proximal femur fracture (IPFF) incidences from $2.1 \%$ to $27.8 \%$ have been reported in primary cementless total hip arthroplasty [9-11]. Surgeons should be aware of this implant-related phenomenon and pay attention to it intraoperatively. Only a few biomechanical studies are addressing the phenomenon of IPFF [12-14]. Even after an intensive search, no publication could be identified that biomechanically analyses the occurrence of IPFF. Therefore, the aim of this biomechanical study was to determine forces necessary to insert the stem and forces which cause IPFF.

\section{Methods}

\section{Measuring setup}

Firstly, a measuring system was developed which was able to measure the forces occurring during the insertion of the femoral stem in a highly dynamic and precise manner. The main component of the measuring system was an impulse hammer (PCB TLD086D05) from PCB Piezotronics (Depew, NY, USA), which had an integrated piezoelectric force sensor. Piezoelectric sensors can measure very highfrequency force signals and are available in small sizes. Furthermore, the housing of the integrated sensor was hermetically sealed so that it could be used in situ and be disinfected afterwards. The impulse hammer is shown in Fig. 1a. It was equipped with an additional weight in order to obtain the same weight $(660 \mathrm{~g})$ as common used surgical mallets. The impulse hammer was connected to a signal conditioner (PCB 482C15), which supplied the sensor and amplified the measuring signal. A data acquisition module with 16 bit $A / D$ converters digitized the analogue signal at a $100 \mathrm{kHz}$ sampling frequency. Afterwards the digitized data were transmitted to a personal computer, where the data were recorded by software specially developed in LabView (NI, Austin, USA).

Figure $1 \mathrm{~b}$ shows the schematic measuring setup. The impulse hammer was used to strike an impactor tool placed at the notch of the femoral stem. The femoral stem CBC Evolution (Mathys Ltd, Bettlach, Switzerland), a common non-cemented Spotorno stem, was used for the implantations. It is laterally symmetrical, i.e., it can be implanted on both left and right sides. This allowed one stem to be used for both sides, which significantly reduced material costs. At the same time, this stem ensured proximal anchorage.

\section{Experimental implantations on human cadavers}


To determine the forces actually occurring during implantation under in situ conditions, femoral stems were implanted in chemically untreated fresh, unfrozen human cadavers (Table 1). All body donors consented to the performance of biomechanical tests after death during their lifetime as part of the body donation agreement. The corresponding hygiene and reverence guidelines for dealing with voluntary body donors were observed at all times. The use of fresh, unfrozen cadavers was important, because their soft tissues were very close to living humans in terms of mechanical properties [15]. The implantations were performed by an experienced senior arthroplasty surgeon (DZ) who used the classic anterolateral approach according to Watson-Jones [16]. The stem sizes were determined intraoperatively by the surgeon. Due to the study structure and the short-term availability of the cadavers at the Institute of Anatomy (Leipzig University), no radiological data could be collected in advance, so that preoperative planning based on X-ray images was not possible. The cadavers always had to be cremated within 24 hours. Also, due to this procedure, the bone density could not be determined.

During insertion of the femoral stems, occurring forces were measured by the impulse hammer and the number of hammer blows required to ensure adequate seating of the stem was counted. Furthermore, the proximal femur was examined for possible fractures following insertion. After successful implantation, further blows were applied to the stem to cause an IPFF (Fig. 2b). These blows were also counted and their force curves recorded. The failure was assessed visually or acoustically by the surgeon. If the surgeon detected a visible fracture or fissure, or if the surgeon heard a crack, the test was stopped.

A descriptive evaluation of the data was carried out using MS Excel (Microsoft Corporation, Redmond, Washington, USA). First, the peak forces, i.e. the maximum force of a hammer blow, were determined from the force curves for each experimental test. The peak force of the last hammer blow at which the failure occurred was indicated as $F_{\text {peak,fail }}$. The Results of the groups were checked for normal distribution with the Shapiro-Wilk test. The normally distributed mean peak forces achieved in the individual experimental trials were then examined for statistically significant differences using the student $t$-test. A value of $P<0.05$ was considered significant. The calculations were performed using SPSS 24.0 (IBM, Armonk, New York, USA).

\section{Results}

Implantations could be performed on two female cadavers (Table 1). One cadaver had identical sized implants on the right and left side. The second cadaver had a slight difference in femora, so the surgeon opted for different sizes. The body donors were 71 and 83 years old and weighed $54 \mathrm{~kg}$ and $65 \mathrm{~kg}$. None of the insertions resulted in fractures of the femur. During stem insertion two, a sensor failure occurred, so no data was available for this test. 
Table 1

Characteristics of cadavers used for the implantations

\begin{tabular}{|c|c|c|c|c|c|}
\hline \multirow[t]{2}{*}{ Implantation } & \multicolumn{3}{|c|}{ Body Donor } & \multirow[t]{2}{*}{ Site } & \multirow[t]{2}{*}{ Stem size } \\
\hline & Sexr & Age & Weight & & \\
\hline 1 & \multirow[t]{2}{*}{ female } & \multirow[t]{2}{*}{71} & \multirow[t]{2}{*}{54} & left & 7 \\
\hline 2 & & & & right & 7 \\
\hline 3 & \multirow[t]{2}{*}{ female } & \multirow[t]{2}{*}{83} & \multirow[t]{2}{*}{65} & left & 8 \\
\hline 4 & & & & right & 9 \\
\hline
\end{tabular}

The applied forces observed during insertion of the stems and the failure tests are listed in Table 2 and shown in Fig. 3. The measured peak forces varied greatly. Forces between $1317.7 \mathrm{~N}$ and $4347.5 \mathrm{~N}$ were determined during insertions and $526.5 \mathrm{~N}$ and $7383.9 \mathrm{~N}$ during the failure tests. The comparison between the two different tests, inserting versus failure, showed significantly higher peak forces $(P<0.001, P<$ $0.001, P=0.002$ ) for the failure test in implantations 1,3 and 4 . The comparison was not possible for implantation 2 because, as mentioned above, there was an error on the sensor. The number of strokes varied greatly in both tests and there was no discernible trend when comparing.

Table 2

Determined peak forces during inserting a femoral stem and failure test

\begin{tabular}{|c|c|c|c|c|c|c|c|}
\hline Implantation & Test & $F_{\text {peak,avg }}(\mathrm{N})$ & $\begin{array}{l}F_{\text {peak, min }} \\
(\mathrm{N})\end{array}$ & $\begin{array}{l}F_{\text {peak,max }} \\
(\mathrm{N})\end{array}$ & $\begin{array}{l}F_{\text {peak, fail }} \\
(\mathrm{N})\end{array}$ & $P$-value & Strokes \\
\hline \multirow[t]{2}{*}{1} & Inserting & $\begin{array}{l}3272.3 \pm \\
619.5\end{array}$ & 1749.1 & 4347.5 & & \multirow[t]{2}{*}{$<0.001$} & 16 \\
\hline & Failure & $\begin{array}{l}4686.3 \pm \\
1301.2\end{array}$ & 1648.5 & 7383.9 & 4350.9 & & 16 \\
\hline \multirow[t]{2}{*}{2} & \multicolumn{5}{|l|}{ Inserting } & & \\
\hline & Failure & $\begin{array}{l}1974.4 \pm \\
658.1\end{array}$ & 526.5 & 3154.7 & 2850.9 & & 54 \\
\hline \multirow[t]{2}{*}{3} & Inserting & $\begin{array}{l}2643.3 \pm \\
462.6\end{array}$ & 1317.7 & 3338.2 & & \multirow[t]{2}{*}{$<0.001$} & 18 \\
\hline & Failure & $\begin{array}{l}3325.0 \pm \\
700.6\end{array}$ & 1297.4 & 4705.1 & 3615.3 & & 28 \\
\hline \multirow[t]{2}{*}{4} & Inserting & $\begin{array}{l}3196.6 \pm \\
595.5\end{array}$ & 1310.9 & 4194.1 & & \multirow[t]{2}{*}{0.002} & 31 \\
\hline & Failure & $\begin{array}{l}4128.2 \pm \\
679.3\end{array}$ & 3151.6 & 4982.2 & 4982.2 & & 6 \\
\hline
\end{tabular}


The results presented in this study provide a basic understanding of the range of forces occuring during the insertion of femoral stems (type Sportono, model CBC Evolution, Mathys Ltd.) and forces leading to an IPFF. Two cadavers could be treated bilaterally. A third screened cadaver had proximal femur fractures treated on both sides with osteosynthesis material still in place. Therefore, biomechanical testing could not be carried out in this case. Due to the small sample size, the observed values are only indicative, as there are many influences such as age, gender, secondary diseases, implant- and surgeon-specific differences and especially the bone mineral density (BMD) [17-20]. As can be seen from the results of the failure test, the fracture did not always occur at the maximum peak force. Only in implantation 4 , the maximum peak force was equal to the failure force. This suggests that the fracture is caused by the interaction between the number of blows and the force level. Therefore, in our opinion, the most important aspect is the presentation and classification of the force ranges of the two different testing methods.

Only a few studies described a similar project or provided comparable data. Both Tijou et al. and Dubory et al. conducted similar biomechanical studies [21,22]. However, they focused their evaluation on the correlation between the number of strokes recommended by a surgeon and by a support system presented by them. Therefore, they did not provide force data [21, 22]. Sakai et al. also investigated the forces required for the insertion of a femoral stem. However, they carried out the investigations on artificial composite femurs and had a much stiffer bearing of the bone than is the case in situ. No information was given on the weight of the hammer. It can be assumed that the stiffer bearing led to the higher observed forces of $9.25 \mathrm{kN} \pm 1.71 \mathrm{kN}$ [23]. In comparison, an average of $3.06 \mathrm{kN} \pm 0.63 \mathrm{kN}$ and a maximum of $4.35 \mathrm{kN}$, i.e. less than half, were determined in our experiments when the stem was inserted. Sakai's submitted forces are even higher than those observed for the failure tests in our study. Therefore, the data were barely comparable.

It is crucial for the success of inserting femoral stems not to exceed the transition point from higher initial stability to fracture. The data given in this study showed a significant difference between the peak forces required for stem insertion and those led to a fracture. Furthermore, between 6 and 54 blows were required for a perceptible fracture after adequate stem stability was established. Therefore, the risk seems to be rather low. But, the fractures were only detected visually and acoustically by the surgeon. However, in many cases, intraoperative fractures due to THA can only be detected via postoperative radiography [9]. Therefore, it is preferable, on the one hand, to provide the surgeon with support systems that recognise a sufficiently high initial stability and, on the other hand, to protect the patient from intraoperative femoral fractures. There are already various concepts for this. Sakai et al. described a close correlation between changes in the sound frequency and the initial stability of stems and the occurrence of fissures in artificial femurs [24]. The finite element analyses described by Sakai et al. were able to show that a decrease in the tone frequency at the hammer is related to an increase in the estimated maximum stress in the femoral shaft. When a decrease in frequency was observed, adequate initial stability of the stem occurred and there was a risk of fracture when hammering was continued. Based on the relationship between stress and frequency, evaluation of frequency shifts can be useful to prevent intraoperative fractures [24]. Another method was described by Tijou et al. who used a hammer equipped with a force sensor to monitor the insertion of femoral stems [22]. The insertion depth of the 
stems were recorded using video motion tracking. Furthermore, the number of strokes and forces at the hammer were recorded. By calculating and evaluating two parameters, their approach allowed them to determine the number of strokes at which the surgeon should stop insertion to obtain optimal initial stability. This study can also be a basic element in the development of a decision support system to assist the surgeon while performing THA [22].

\section{Limitations}

This is a small case series resulting from the limited resources of suitable cadavers, costs for the examinations and time-limited availability until cremation. Therefore, only two cadavers could be treated. As a further consequence of time-limited availability, the BMD of the cadavers, as a factor influencing failure behaviour, could not be determined.

Furthermore, the surgeon considered the striking pad of the hammer used to be too small. As a result, occasionally the impactor tool was only partially hit, which caused a too small force measured by the sensor. However, this influence was largely eliminated, as the measurement only started when a force of $500 \mathrm{~N}$ was exceeded due to the software.

\section{Conclusions}

The biomechanical experiments presented in this study have shown that even with the small number of implantations, significantly higher hammering forces were required to cause a visually or acoustically perceptible IPFF than were necessary for adequate seating of the femoral stem. However, as fractures are described in the literature with a relatively high incidence and often cannot be perceived acoustically or visually, it is important to advance the development of supporting systems for intraoperative use as presented here.

\section{List Of Abbrevations}

\begin{tabular}{|cl|}
\hline THA & Total hip arthroplasty \\
\hline IPFF & Intraoperative proximal femoral fracture \\
\hline BMD & Bone mineral density \\
\hline
\end{tabular}

\section{Declarations}

\section{Ethics approval and consent to participate}

Institutional approval was granted for the use the post-mortem tissues in this study under the Saxonian Death and Funeral Act of 1994 (third section, paragraph 18 item 8) 


\section{Consent for publication}

Not applicable

\section{Availability of data and materials}

The datasets used and analysed during the current study are available from the corresponding author on reasonable request.

\section{Competing interests}

The authors declare that they have no competing interests.

\section{Funding}

This work was funded by the "Zentrales Innovationsprogramm Mittelstand - ZIM" (Central Innovation Programme for SMEs) no. 944000-033 granted to PD Dr. med. habil. Torsten Prietzel.

\section{Authors' contributions}

TW carried out all experiments and was a major contributor in writing the manuscript.

SS designed the figures of the manuscript and was a major contributor in writing the manuscript

TP was a contributor in terms of writing of the manuscript and of interpretation of the data.

RM conducted the statistical analysis of the data.

AR developed the concept of the study and did the literature research.

DZ provided the idea to the study and developed the concept of the study. Furthermore he performed the implantations on cadavers and was a contributor in writing the manuscript.

All authors read and approved the final manuscript.

\section{Acknowledgements}

The authors would like to thank Thomas Wolfskämpf and Matthias Oehme for their support with managing the acquisition of human cadavers for this study. Furthermore, the authors would like to thank the manufacturer Mathys AG for the cooperation and providing the prosthesis components. 


\section{References}

1. Varacallo M, Luo TD, Johanson NA. StatPearls: Total Hip Arthroplasty (THA) Techniques. Treasure Island (FL); 2020.

2. Neuprez A, Delcour J-P, Fatemi F, Gillet $P$, Crielaard J-M, Bruyère $O$, Reginster J-Y. Patients' Expectations Impact Their Satisfaction following Total Hip or Knee Arthroplasty. PLoS One. 2016;11:e0167911. doi:10.1371/journal.pone.0167911.

3. Yamasaki T, Yasunaga Y, Mori R, Hamanishi M, Shoji T, Ochi M. The Cementless Spotorno stem in THA: 10 year results. Hip Int. 2014;24:98-102. doi:10.5301/hipint.5000068.

4. Müller LA, Wenger N, Schramm M, Hohmann D, Forst R, Carl H-D. Seventeen-year survival of the cementless CLS Spotorno stem. Arch Orthop Trauma Surg. 2010;130:269-75. doi:10.1007/s00402009-0969-7.

5. Spotorno L, Romagnoli S, Ivaldo N, Grappiolo G, Bibbiani E, Blaha DJ, Guen TA. The CLS system. Theoretical concept and results. Acta Orthop Belg. 1993;59 Suppl 1:144-8.

6. Singh M, Nagrath AR, Maini PS. Changes in trabecular pattern of the upper end of the femur as an index of osteoporosis. J Bone Joint Surg Am. 1970;52:457-67.

7. Mert M, Ermutlu C, Kovalak E, Ünkar E, Okur SÇ. Long term survival analysis of cementless Spotorno femoral stem in young patients. Acta Orthop Traumatol Turc. 2019;53:19-23. doi:10.1016/j.aott.2018.11.004.

8. Biemond JE, Pakvis DFM, van Hellemondt GG, Buma P. Long-term survivorship analysis of the cementless Spotorno femoral component in patients less than 50 years of age. J Arthroplasty. 2011;26:386-90. doi:10.1016/j.arth.2009.12.017.

9. Miettinen SSA, Mäkinen TJ, Kostensalo I, Mäkelä K, Huhtala H, Kettunen JS, Remes V. Risk factors for intraoperative calcar fracture in cementless total hip arthroplasty. Acta Orthop. 2016;87:113-9. doi:10.3109/17453674.2015.1112712.

10. Timmer C, Gerhardt DMJM, Visser E de, Kleuver M de, van Susante JLC. High incidence of intraoperative calcar fractures with the cementless CLS Spotorno stem. Eur J Orthop Surg Traumatol. 2018;28:1291-6. doi:10.1007/s00590-018-2217-8.

11. Ponzio DY, Shahi A, Park AG, Purtill JJ. Intraoperative Proximal Femoral Fracture in Primary Cementless Total Hip Arthroplasty. J Arthroplasty. 2015;30:1418-22. doi:10.1016/j.arth.2015.02.043.

12. Jakubowitz E, Seeger JB, Lee C, Heisel C, Kretzer JP, Thomsen MN. Do short-stemmed-prostheses induce periprosthetic fractures earlier than standard hip stems? A biomechanical ex-vivo study of two different stem designs. Arch Orthop Trauma Surg. 2009;129:849-55. doi:10.1007/s00402-0080676-9.

13. Jakubowitz E, Seeger JB, Kretzer JP, Heisel C, Kleinhans JA, Thomsen M. The influence of age, bone quality and body mass index on periprosthetic femoral fractures: a biomechanical laboratory study. Med Sci Monit. 2009;15:BR307-12. 
14. Thomsen MN, Jakubowitz E, Seeger JB, Lee C, Kretzer JP, Clarius M. Fracture load for periprosthetic femoral fractures in cemented versus uncemented hip stems: an experimental in vitro study. Orthopedics. 2008;31:653.

15. Lim Y-J, Deo D, Singh TP, Jones DB, De S. In situ measurement and modeling of biomechanical response of human cadaveric soft tissues for physics-based surgical simulation. Surg Endosc. 2009;23:1298-307. doi:10.1007/s00464-008-0154-z.

16. Watson-Jones R. Fractures of the neck of the femur. Br. J. Surg. 1936;23:787-808. doi:10.1002/bjs.1800239213.

17. Song Y, Beaupre G, Goodman SB. Osseointegration of total hip arthroplasties: studies in humans and animals. J Long Term Eff Med Implants. 1999;9:77-112.

18. Lamb JN, Baetz J, Messer-Hannemann P, Adekanmbi I, van Duren BH, Redmond A, et al. A calcar collar is protective against early periprosthetic femoral fracture around cementless femoral components in primary total hip arthroplasty: a registry study with biomechanical validation. Bone Joint J. 2019;101-B:779-86. doi:10.1302/0301-620X.101B7.BJJ-2018-1422.R1.

19. Carli AV, Negus JJ, Haddad FS. Periprosthetic femoral fractures and trying to avoid them: what is the contribution of femoral component design to the increased risk of periprosthetic femoral fracture? Bone Joint J. 2017;99-B:50-9. doi:10.1302/0301-620X.99B1.BJJ-2016-0220.R1.

20. Russell LA. Osteoporosis and orthopedic surgery: effect of bone health on total joint arthroplasty outcome. Curr Rheumatol Rep. 2013;15:371. doi:10.1007/s11926-013-0371-x.

21. Dubory A, Rosi G, Tijou A, Lomami HA, Flouzat-Lachaniette C-H, Haïat G. A cadaveric validation of a method based on impact analysis to monitor the femoral stem insertion. J Mech Behav Biomed Mater. 2020;103:103535. doi:10.1016/j.jmbbm.2019.103535.

22. Tijou A, Rosi G, Vayron R, Lomami HA, Hernigou P, Flouzat-Lachaniette C-H, Haïat G. Monitoring cementless femoral stem insertion by impact analyses: An in vitro study. J Mech Behav Biomed Mater. 2018;88:102-8. doi:10.1016/j.jmbbm.2018.08.009.

23. Sakai R, Takahashi A, Takahira N, Uchiyama K, Yamamoto T, Uchida K, et al. Hammering force during cementless total hip arthroplasty and risk of microfracture. Hip Int. 2011;21:330-5. doi:10.5301/HIP.2011.8408.

24. Sakai R, Kikuchi A, Morita T, Takahira N, Uchiyama K, Yamamoto T, et al. Hammering sound frequency analysis and prevention of intraoperative periprosthetic fractures during

\section{Figures}




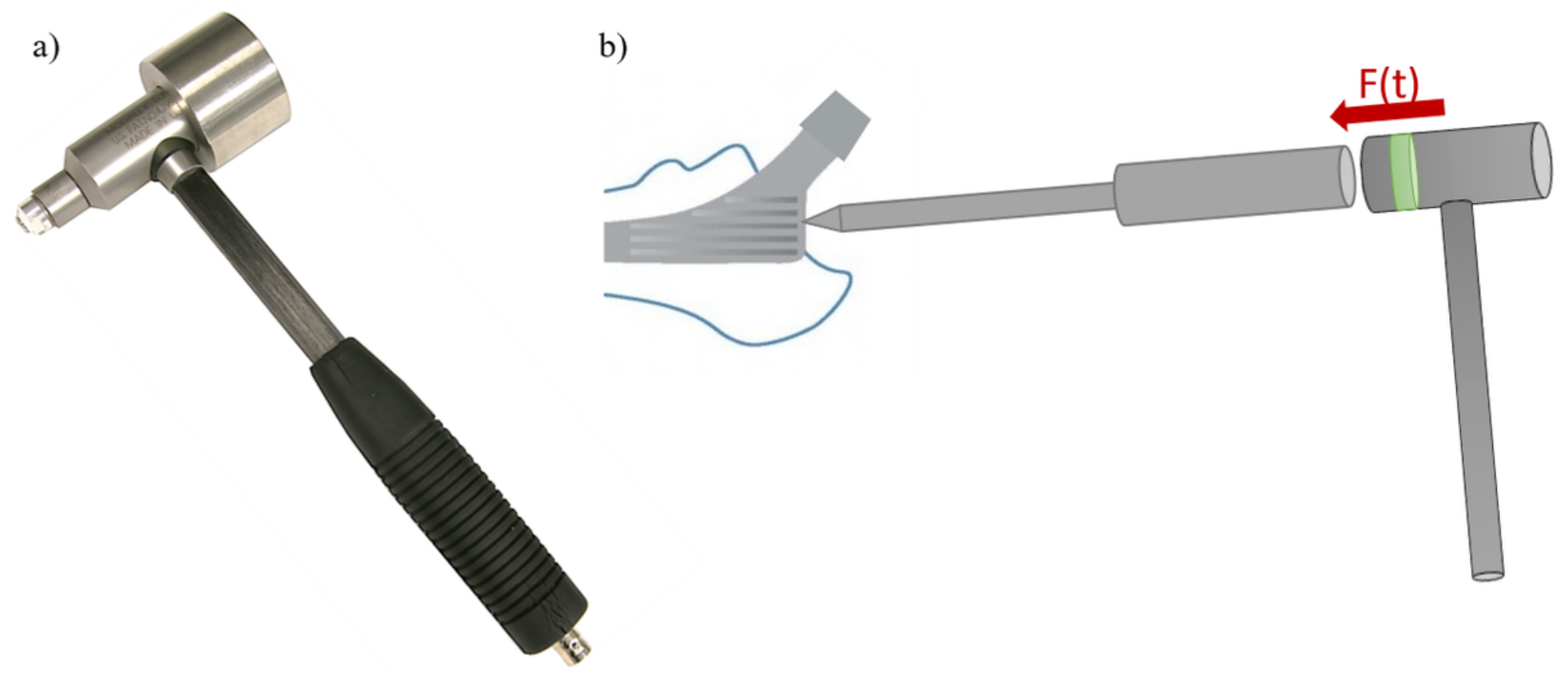

\section{Figure 1}

(a) Impulse hammer, (b) Schematic of measuring setup
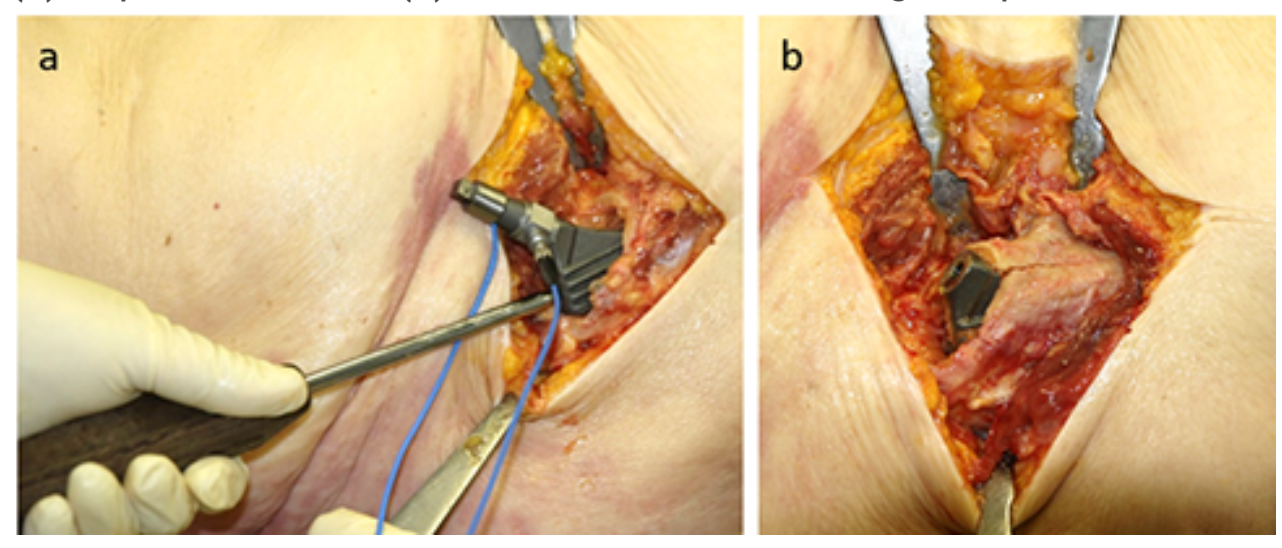

Figure 2

(a) Inserting a modified stem (CBC Evolution, Mathys AG) into the femur of a cadaver; (b) Fractured proximal femur of a cadaver following a test to failure 


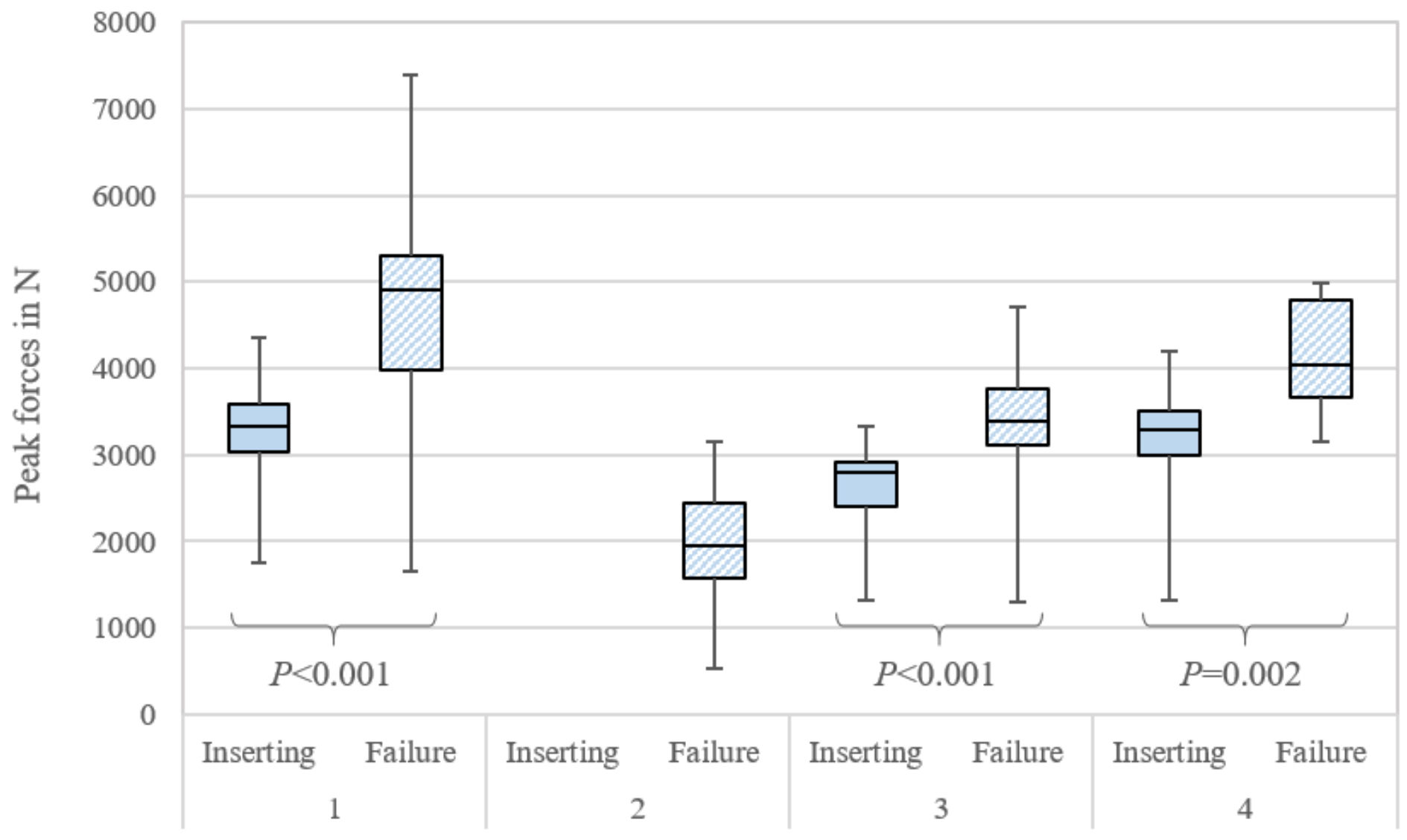

Figure 3

Box plot with determined peak forces during inserting a femoral stem and failure test 